\title{
HOW TO ENHANCE THE EFFECTIVENESS OF THE LEARNING PROCESS DURING DISTANCE LEARNING. PSYCHOLOGIST RECOMMENDATIONS
}

\author{
Tamar Kapanadze ${ }^{*}$ \\ Tbilisi Classical Gymnasium, T'bilisi, Georgia, E-mail: kapanadzetamuna0@gmail.com
}

(Received: July 2021; Accepted: October 2021; Published: December 2021)

\begin{abstract}
Effective management of the learning/teaching process in distance learning is one of the major challenges facing education, especially now in the Covid-19 pandemic. The list of problems mainly combines social and interactive aspects. This article provides tips to help the student increase motivation, overcome feelings of social isolation, find alternative ways of communicating and, develop communication skills. The aim of the research is to identify the pros and cons of online learning, thus finding out how to improve the effectiveness of the learning process during distance learning. The research was obtained through a focus group, the research was conducted in Tbilisi public schools, students, teachers and parents participated in the focus groups. After analyzing the data, it was found that participants positively see such a form of teaching, which in turn would have a positive impact on students' academic performance, but they also talk about small negative aspects.
\end{abstract}

Keywords: Distance Learning; Asynchronous Learning; Communication Skills development; Social Isolation; Motivation.

\section{Introduction}

If we review the history, we will find that online learning does not have a long history. The term "online learning" was sounded for the first time in 1999. Still, there are a few facts about that Online learning still existed in the 19th century. Still, before the Internet would exist, in 1840 Isaac Pitman (Isaac Pitman 1813-1897) taught students about shorthand by mail.

Joshua Stern in his study says, "Online Teaching and Learning Introduction, (Introduction to Online Teaching and Learning) explains online education - "Online education is education that takes place on the Internet. It is often referred to as elearning. Online education can be both e-courses and online universities, schools or other". (Stern, 2005, p.2)

\footnotetext{
*Corresponding author: Tamar Kapanadze.E-mail: kapanadzetamuna0@gmail.com
}

Copyright (C) 2021 The Author(s). Published by VGWU Press

This is an Open Access article distributed under the terms of the Creative Commons BY 4.0 license (Creative Commons - Attribution 4.0 International - CC BY 4.0) which permits unrestricted use, distribution, and reproduction in any medium, provided the original author and source are credited. 
How to Enhance the Effectiveness of the Learning Process during Distance Learning. Psychologist Recommendations

In the 20th century, with the development of computer technology and thanks to the Internet, online learning is becoming even more widespread acquires and develops. People have the opportunity to own a computer and get more information using the internet.

Initially, the online teaching method was used by most universities appealed to students who for various reasons did not have the opportunity to attend lectures, to be able to gain knowledge. "There are many people who want their own knowledge deepening but failing to do so over time, geographically due to location or capabilities. Our best possible solution is distance learning. "- Stephen Downs (Stephen Downes, "E-learning" 2005). Online learning has many facets. Psychologist Robert Feldman in his book "Teaching and Learning Online" describes the types of online learning.

There are two types of online training, synchronous and asynchronous. Direct connection (chat), audio is used during synchronous training and video conferencing, data and statistics exchange, online slide shows and multimedia presentations. Even during asynchronous teaching use email, uploaded files and long discussions on forums. (Feldman, 2002, p.6)

A 2008 study by Johan Lundberg, David Castillo Merino, and Mounir Dahmani on the topic of whether or not online students learn better compared to students (Do Online Students Perform Better than Face-to-face Students?) So, the conclusion turns out that students who

Attended online courses as well as obtained any type of degree online. In universities, they get higher scores on exams than those who were engaged in the method of face-to-face teaching. (Lundberg, 2008, p. 40).

As we have already mentioned the practice of distance learning [1] is almost 180 years old. Firstly, it was processed by mail, asynchronously [2]. With the help of technological progress in the 21 st century, the means of communication have been refined and diversified. The problem of time spent on "information travel" has been solved, distance learning has become more convenient and holistic. Problems have also increased in the wake of capacity building. Proper technology, a quality Internet, computer programs, and the prerequisite for effective distance learning of their correct use. At the same time, mass training on devices suitable for teaching and the effective use of programs remain a problem to this day. Need to use similar problems, but not enough.

Various factors influence student involvement and motivation in distance learning. Social-interactive, personal and environmental factors are distinguished from them. School and family play a leading role in student motivation. When switching to distance learning at a fast pace, both parties have to reorganize, act flexibly to change the teaching principle and the agenda. Students' grievances are also varied as direct 
Kapanadze, T., (2021)

How to Enhance the Effectiveness of the Learning Process during Distance Learning. Psychologist Recommendations

delivery of learning strategies online, the problem of operating independently in this space, lack of self-efficacy [3], and socialization, which ultimately makes the learning process tiring.

\section{Main part}

\subsection{Negative impacts of distance learning}

Like traditional education, distance learning has its pros and cons. According to the studies and opinions of various authors, the list of major problems combines social and interactive aspects. Added to this is a less structured environment, which, as a whole, lowers students' sense of responsibility and motivation.

Personal factors are also evident. Students point out that while learning online, along with a lack of socialization, you suffer from a lack of motivation, self-discipline, and self-regulation. It is important to note that these factors also affect the student's family, school, and teacher. As a result, a systemic problem is created, each component of which is interdependent.

\section{What are the challenges faced by teachers?}

The main problem of teachers is related to the development of a space fundamentally different from the classical teaching methods.

Their role is changing. If the previous teacher only had to adapt to the pedagogical function, in distance learning he or she has to provide additional materials for the student, provide them with communication via the Internet, adapt the lesson process to digital means of communication, and introduce learning systems to children or parents. (Bonk \& Dennen, 2003).

Teachers distinguish between two types of problems: on the one hand, new technical needs have arisen because of the frequency of the Internet, the quality of equipment, software, and their efficient use. On the other hand, qualitative changes are directly related to the conduct of the lesson. Teachers point out that often students, even in terms of technical support, avoid turning on the camera.

However, parental involvement is rarely sufficient. An additional difficulty is working with students with special educational needs. Finally, these factors also affect teachers' attitudes uncontrollably, and new space leads to a feeling of incompetence in them.

\section{What are the challenges faced by parents?}

Parents' involvement and support in both classical and distance learning have a positive impact on a child's education (Garbe et al,, 2020). The change in the format of education administration will have a direct impact on the schedule and 
How to Enhance the Effectiveness of the Learning Process during Distance Learning. Psychologist Recommendations

responsibilities of the student's family members. They have new, unknown responsibilities. In distance education, the parent becomes the teacher's assistant, who has similar responsibilities. New responsibilities are attached to job responsibilities and homework.

New responsibilities are attached to job responsibilities and homework. The parenting capabilities are limited, hence the pressure and tension increase. Even in large families, it becomes almost impossible to control the situation. The task becomes even more difficult when the parent is unprepared for the news agenda. For example, do not have the appropriate hardware or software, or workspace at home. With technical unpreparedness, parents often do not have the appropriate pedagogical education. This is accompanied by inadequate feedback from teachers and poorly adapted curricula and assignments in the digital space. The change in the role of parents and active involvement in the teaching process also changed their attitude towards the educational process. The student's family members highlight problems related to the tedious lesson routine and lack of informal activities. An additional concern for family members is that the teenager may be overly attached to the screen.

\section{What are the challenges faced by students?}

Given the above, the students faced several difficulties. Which can be divided into several areas:

\subsection{Lack of live communication}

Communication involves the transmission, reception, or exchange of thoughts, feelings, or information through language. It requires the sender, the sender, and the receiver. Lack of communication, in itself, does not only mean a lack of relationship between a teacher and student. It also applies to other groups, namely: parent and school, parent and teacher, teacher and school, teacher and student, and pupil and student. It is implied that the lack of a common physical space disrupts the living, natural flow of communication. Therefore, it is necessary to introduce the process artificially in the online space. Students receive insufficient feedback from the teacher, children are less involved in the lesson process, teamwork is reduced. As a result, students do not have a sense of social belonging. This negatively affects their motivation and sense of responsibility.

\subsection{Development of communication skills}

The function of schools and educational institutions, in general, is not only to provide information. School plays an important role in the development of a child's social and communicative competence, which is essential for healthy psycho-social 
Kapanadze, T., (2021)

How to Enhance the Effectiveness of the Learning Process during Distance Learning. Psychologist Recommendations

development. To acquire this competence, it is necessary to express one's thoughts and feelings in the right way and to develop the skills of adequate understanding and interpretation of other people's signals, messages. The two main types of communication are verbal and non-verbal communication.

Verbal communication is established through language. In addition to conveying the utterance phonologically, morphologically, or syntactically, the language also includes the pragmatic part. This, in itself, implies following social rules in the process of dialogue or monologue, gaining knowledge of when a dialogue should end, following a line, asking or answering a question. Also, randomly, how to maintain or change the topic of the conversation. Adherence to social rules also implies courtesy, general manners, and so-called etiquette. The development of communication skills also involves the assimilation of cultural rules. Pragmatic skills are highly dependent on social intelligence, the ability to understand, express, and manage the emotions of others and oneself, and to require self-awareness. Also, written communication is noteworthy, which some authors even single out. Written communication is any interaction that takes place through written text. For example, a short text message, email, textbook, or written instruction.

Non-verbal communication involves the transmission and comprehension of information beyond language. It combines different aspects of body language, such as gestures, facial expressions, posture, touch, eye contact, distance in speech, and the proper use and understanding of other actions. Added to this is prosody, which includes the characteristics of sound in the speech process - pitch, tempo, melody, and intonation of speech. Like written communication, some authors single out visual communication - the use of graphic means to convey any content. Examples of this are the use of tables and graphs, selecting the correct colors or text size when presenting a presentation, and so on.

In distance learning, it can be said that students develop more written and visual forms of communication and fewer others. The development of communication skills should include all its forms. Consequently, distance learning threatens the harmonious development of student's communication skills.

\subsection{The feeling of social isolation}

According to Lev Vygotsky's, theory, of social development, social interaction plays a leading role in the development of a child. Numerous authors emphasize the feeling of social isolation in students during distance learning. In the classical education system, learning is a social process - knowledge is created through direct interaction between the teacher and the children in the lesson. This applies to both academic and social knowledge. Moving the educational process to the digital space poses a threat not only to the child's cognitive but also to emotional development. Students expect 
How to Enhance the Effectiveness of the Learning Process during Distance Learning. Psychologist Recommendations

adequate and prompt feedback from the teacher. Consequently, in distance learning, against a background of attention deficit, feelings of social isolation and loneliness increase. Added to this is the lack of emotional involvement, which is negatively impacted by the lack of informal communication space between lessons. In the high school age, this is already an urgent problem. Children of this age are sensitive to social challenges, and their self-esteem is very low. Social isolation hurts a child's academic performance, mental and physical health. (Fontaine et al., 2009; HallLande et al., 2007; Qualter et al., 2010; Goodenow, 1993).

\subsection{Motivation}

Motivation is a person's willingness to make physical and/ or mental efforts to achieve a goal or result. It is often seen as the driving force behind the learning process. There is a difference between intrinsic, i.e., internal and extrinsic, i.e., external motivation. Both are related to academic achievement and learning satisfaction. We have already discussed several issues related to distance education that have an impact on student motivation, including:

1. Feelings of social isolation, which are significantly related to communication.

2. Lack of self-efficacy, which is caused by the lack of technical competence, difficulties in self-regulation, and time management. If it is difficult for a child to operate online, he/she has difficulty achieving the ultimate goal - in this case, learning the material. As a result, the student encounters the expectation that he or she will not be able to master the material.

3. Inefficient use of digital space means that the teacher should make the most of digital technology and make the lesson process or preparation more interesting and fun.

Thus, a lack of natural, lively communication increases the risk of social isolation and negatively affects the development and motivation of communication skills. All of this ultimately hurts the effectiveness of teaching.

Given these difficulties, the following questions need to be answered: How should communication between different groups be enhanced? How to develop student communication skills in distance learning? How to reduce the feeling of social isolation that does not only bother students?

\section{How to avoid the negative effects of distance learning}

It has already been mentioned that involvement in distance education is almost equally the responsibility of the child's family members and teachers. However, involvement alone is not enough - the coordinated work of guardians and teachers, the sharing of strategies and principles of student relations are crucial. Besides, the 
Kapanadze, T., (2021)

How to Enhance the Effectiveness of the Learning Process during Distance Learning. Psychologist Recommendations

school as a whole is involved in the process, providing information, assistance, and assistance to teachers, parents, and students.

The school creates a sense of unanimity in those activities associated with it. For this, various authors consider it important to define a distance learning policy and publish a relevant document. The protocol should include a list of computer programs used in distance learning, a list of school staff, as well as roles and responsibilities of students and parents, variations in student assessment methods, a definition of inappropriate behavior in distance learning, and a list of punitive conditions. The result is a certain context that unites different people.

It has already been said above that the teacher is responsible for encouraging student interaction in online learning. The school owes the same to teachers. Feelings of social isolation are not just a problem for students. It has been proven that this factor also has an impact on teachers' satisfaction and the likelihood of future involvement in online learning (Childers \& Berner, 2000). An environment must be created for teachers to have a sense of responsibility, equality, and support. If necessary, he should count on the support of the school and the principal. It is recommended studying the computer skills and technology of teachers, other staff, students and parents. After the competency test, it is necessary to identify the existing problems and outline ways to solve them. However, reporting to teachers should not be a cause for stress.

The preparation period is important for establishing communication. At this point, agreements are made and certain expectations arise. At this stage, the school team informs the teachers and the student's parent or guardian about the general vision of the school, the distance learning process, explains their functions and responsibilities, and conducts pieces of training as needed. Successful communication during the preparation phase helps to reduce anxiety. Finally, the principal is responsible for being calm, balanced, and empathetic toward teachers, students, or their guardians.

The first step for a teacher to learn remotely is to get to know his or her students and gain their trust. This process is especially difficult with first graders because they do not have the function of a teacher in a structured environment, and it is not an authority for them. To build trust, students need to feel cared for, valued, and safe. To do this, the teacher can talk about personal interests, life details and introduce the students to this. For example, they can show children their favorite photos and push them to do the same. At this time the line should be filled with positive details. This will help them to present themselves and get to know each other better. On a similar principle, the teacher can ask students about a favorite animal, game, or color. In larger classes the focus should be on the interests of the children, a favorite color or animal may be replaced by a favorite athlete, actor, character, or musician. 
Most students use the technique naturally and spontaneously. For many teachers, however, the process is associated with obstacles. As mentioned above, this often leads to a feeling of incompetence in them. In some cases, the student may be better able to cope with technical problems during the lesson. It is permissible to take advantage of this situation if we take into account that learning is a two-way process, and it is useful to receive information or instructions from the student. In case of technical deficiencies in the lesson process, the teacher can recognize that this is a new situation for him/her in which he/she is not skilled and ask for help from the students. This action can bring several benefits:

Students are better aware that there may be a lack of knowledge, and this is not a tragedy, asking for help is not a weakness. At the same time, children will increase their emotional involvement because they feel that their actions have a real impact on the environment and are therefore important.

Due to the lack of live communication, it is difficult for the teacher to notice the emotional needs of the child. Consequently, it is difficult to support the child, which complicates the formation of emotional attachment. The teacher can communicate informally with the child to thaw the ice. Periodic and direct communication with the student by phone or video is recommended. This can make the children feel better about caring for the teacher.

For a sense of security, it is necessary to use positive behavior management strategies. This includes encouraging desirable behavior, setting an example, and ignoring unwanted behavior. Evaluation should focus on behavior and not personality. Here, it should be noted that communication with the family should not be limited to negative information. Attention should also be paid to the positive aspects of student behavior.

Feedback is essential for communication control. Numerous studies have highlighted the importance of instant feedback. The latter implies an immediate reaction to a particular behavior. According to the behaviorist approach, this is a prerequisite for learning. Instant feedback is only possible during synchronous teaching [4], in the teaching process. To do this, the teacher must observe the children's involvement and emotions when delivering the material. Concreteness is also necessary - the student must understand specifically what is acceptable and what is unacceptable in behavior. In the latter case, it is necessary to provide an alternative strategy of behavior (for example, do not count the answer to the question, then raise your hand and it will count). Student behavior in the digital space is very difficult to perceive, especially if the cameras are off. The likelihood of the camera turning on may increase with the use of different backgrounds that come with certain computer programs. It is possible to use these wallpapers thematically, for example, if the lesson is about Rome, have students and teachers use a suitable image as a 
Kapanadze, T., (2021)

How to Enhance the Effectiveness of the Learning Process during Distance Learning. Psychologist Recommendations

background. This will diversify the lesson process; however, it resolves a specific situation when students do not turn off the camera due to family circumstances.

Asynchronous learning is mainly based on feedback. Assignment feedback in elementary grades should be visual, implying the use of a graphic facial enhancer (e.g., stickers). Teacher feedback from middle and high school students should be highly informative. Superficial evaluation of the work - good or bad - does not increase the effectiveness of teaching. Feedback should allow the student to conclude both the outcome and the process. It should reflect the difference between the desired and actual performance and the ways to achieve the set goals. It is necessary to emphasize the positive as well. Remarks should not take the form of reprimand, otherwise, along with the deterioration of the psychological and emotional background, the child's involvement will also decrease.

It is very important to use active learning strategies for student involvement in the lesson process, along with feedback. Active learning is a student-centered educational approach that requires teaching through material interaction. To encourage this, the teacher should pay less attention to the transmission of information and focus on improving the student's skills (e.g., reading, writing, discussion). The teacher can give the students illustrative examples when explaining the lesson. This is especially important in the elementary grades as it promotes selfreflection and self-monitoring.

However, the lesson process should focus on stimulating visual or auditory perception, which can be the use of different animation effects, interactive programs, and different sound effects during the presentation.

To increase engagement, it is effective to set goals, break them down into components, and assist relevant platforms to achieve this. For example, use auxiliary spreadsheets and reminder software tools. This will show the students the order of the day, week, or semester.

Involvement in the teaching process and in general, the effectiveness of teaching depend on the student's satisfaction. It may be enhanced by unexpected rewards (e.g., games), positive feedback, consideration of student expectations, and an explanation of the practical application of the learning material.

To prevent lack of communication and social isolation, it is advisable to encourage group work, online discussions, and group chats within a specific subject. In numerous classes, they are recommended to divide students into small groups (3-5 children) and changing their composition from time to time. The feeling of social belonging in the relatively upper classes may increase the so-called. Use of Wikis A common database where it is possible to collaborate to create or edit content remotely. Digitizing the school library is recommended ensuring that children have access to quality information. A common explanatory dictionary can be made on a 
How to Enhance the Effectiveness of the Learning Process during Distance Learning. Psychologist Recommendations

similar principle, for example, when teaching hagiographic works. This is made possible by several platforms, such as Google Docs. These types of activities enhance the sense of social belonging that is crucial to a teenager's healthy emotional development. It should be noted that the use of social networks in distance learning is not recommended. These platforms promote excessive familiarity, which can be a source of inconvenience for both parties. For adolescents, in particular, moving the classroom and social identities into one space is a potential source of tension.

They are recommended using mixed methods of distance learning to develop different aspects of communication, in which case synchronous time will be devoted to two-way communication, discussions, and group work. The opposite approach is when the teacher opens the lesson and the students listen to it passively. Asynchronous communication, on the other hand, is better directed at sending written or visual assignments and receiving feedback on them.

As mentioned above, the student's sense of self-efficacy is compromised when moving the classroom environment to a new, digital space. Academic self-efficacy is closely related to student success (Yokoyama, 2019). There are four main sources of this feeling: successful experience, social modeling, persuasion, and monitoring emotional arousal. In practical terms, at the beginning of distance learning, teachers can use flawless teaching techniques [5] and then gradually it is possible to complicate the questions or material. When watching another person's success, a person believes in the possibility of his or her success. In this regard, it is recommended that students share their experiences of coping with difficulties. Especially if any student is facing some problem. When a person believes he or she can overcome a challenge, he or she puts in even more effort. In this regard, teachers and parents need to encourage children and convince them of their competence. Monitoring emotional arousal in distance learning is largely a family responsibility. Guardians should monitor how nervous and anxious the child is about the lesson process and take care to balance that.

A student's family members should have active communication with teachers or other school staff. To do this, the student's parent or guardian should contact them for any advice, interview or to find out the child's involvement. Feedback may take 1 or 2 days. However, you should not overlook the increased pressure under which the teacher is.

To facilitate socialization, it is recommended for the parent to carry the child in different circles, to use playgrounds and recreational spaces. If a parent is unable to allow a child to play in the physical space, he or she should also allow the child to play online with classmates or friends. There is often a negative attitude towards computer games although some games not only hurt but even contribute to the development and socialization of the child. When talking about games, the main 
Kapanadze, T., (2021)

How to Enhance the Effectiveness of the Learning Process during Distance Learning. Psychologist Recommendations

questions are: "Which one?", "how long?" And not whether it is possible to use them. Almost every game has a defined age limit that a parent should be aware of. It is also recommended that a child should spend 1 hour in front of a screen in elementary school, although this time should not be used cluttered. It is recommended to divide this time into 30-30 minute sessions. In relatively high-class computer games are allowed for no more than 2 hours. Preferably, the game should be a group for which children will need to communicate synchronously.

School-age is heterogeneous, and the challenges are varied. We face a very specific challenge in the elementary grades. In particular, sensory and motor development. To facilitate this, it is recommended incorporating assignments in different subjects, for the completion of which children are required to color, draw, cut, etc. Additionally, popular handicrafts (for example, origami) can be promoted. It is also possible to facilitate more movement in the distance learning process. For example, while learning geometric shapes, children may be encouraged to look for items in their home or yard that have a circle, rectangle, square, triangle, and so on. Form. Or, regardless of the lesson material, the teacher should apply the following game: Every child should find a specific item in the house (for example, a comb). The winner is the one who finds it first.

\section{How to create an informal environment and a positive psycho-emotional background?}

Informal activities are important to create a positive mood for students. This is especially true at the beginning of learning. Listed below are some of the recommended non-formal learning activities:

1. The Teacher sends the name of an object or character to one of the students in the personal chat, and the child has to represent it. The goal of the rest of the class is to understand what or whom the student represents.

2. The teacher writes the name of the object in the personal chat of one of the students. The child should start drawing this object on the interactive whiteboard. The rest of the classmates aim to guess the object. The winner is the one who will be able to do it the fastest. If you do not have an interactive whiteboard, you can use a screen sharing feature and a combination of Microsoft Paint or Microsoft PowerPoint.

3. The teacher turns off his/her microphone and very slowly says a short, common word (for example, bread). The students aim to guess this word by the movement of the person. The winner is the one who manages to do it first.

4. All children's microphones are off. Then one of them covers his eyes with his hand. At this point, the teacher will turn on the microphone for one child to say a

52 Sciendo Journal of Legal Studies Volume 28 Issue 42/2021

ISSN 2457-9017; Online ISSN 2392-7054.

Web: publicatii.uvvg.ro/index.php/jls. Pages $42-57$ 
How to Enhance the Effectiveness of the Learning Process during Distance Learning. Psychologist Recommendations

specific word (e.g., hello). Throughout this process, the blindfolded student aims to guess who said the word.

5. The teacher asks one of the students to describe the item that is closest to the right of him. The goal of the rest is to guess what this child is talking about. The winner is the one who guesses first. Using an interactive whiteboard or screen sharing, this activity can take the form of a famous game "hanging".

6. A pleasant practice is online excursions or movie screenings. These two are recommended when similar collective activities cannot be performed in the physical space.

In the online lesson process, teachers often use the student microphone mute function. Despite the comfort, this may harm the student's emotional state - the child will experience a feeling of neglect. Instead of turning off the microphone, the teacher can work on the children's behavior: Agree in advance when you can talk and when you cannot, when the child should demand attention, explain why turning off the microphone is important, explain that the teacher is disturbed by the noise and the students have to turn off the microphone themselves. The teacher can use this function when the student violates the above rules. Then the teacher must explain the reason for his or her action to the child.

\section{How to develop a healthy attitude towards online learning as an institution?}

Online learning is often not perceived by students as an educational institution that has its own rules. As mentioned above, to correct this, the child should have a sense of social belonging. In the online space, the school should have its site and a convenient platform for social interaction. A sense of belonging may be enhanced by placing the school logo on learning platforms, which, to some extent, reminds the student that this is a normal work process. Despite the school's efforts, the biggest pressure in this regard comes from teachers and parents.

One of the advantages of asynchronous learning is the flexibility of the schedule. Teachers and parents should develop a daily schedule for each student. The teacher should set aside certain hours to answer students' questions to increase feedback. He is also responsible for maintaining the framework of the teaching process. Nonpunctuality, interruption of lessons or overly informal attire are not allowed. More involvement from parents is needed. In particular, the parent is obliged to:

1. Provide a child with a routine - the child should have a set schedule and follow it. Wake up in the morning, tidy up, tidy up your bed, have definite hours of study, sleep, and fun, and so on. The child should analyze that, despite the lack of physical space, distance learning has its rules.

2. Give the child a desk or room - Creating a work environment for the student is very important. The child should be in a quiet place where he or she can concentrate. 
Kapanadze, T., (2021)

How to Enhance the Effectiveness of the Learning Process during Distance Learning. Psychologist Recommendations

Self-control is still brewing at school age. Therefore, there should be no distractors in the study space.

3. Check the child's activities during the day before the lessons start, the parent should ask the child what subjects he/she has today, whether he/she has any kind of survey or test, how he/she intends to manage time, what materials he/she will need during the day and how he/she will be able to help. These questions will help the student formulates day-to-day expectations and perceived parental support. At the end of the day, summarizing questions should be asked: what tasks did he perform, what did he discover new and what were the difficulties in the process.

4. Promote the independence of the child - the parent's learning processes cannot be continuously involved. He must grasp that childhood was gradually able to attend lessons independently and prepare them. This process can be difficult for a child to discover and require a lot of effort. At this point, the parent should report the experience slowly, without excessive care.

\section{Research Methodology}

This study was conducted through a focus group method. The advantage of the focus group is that this method allows us to keep an eye on the thought formation process and, at the same time, try to determine why respondents think the way they think. This happens during the exchange of views between group members.

Focus group A type of group interview whose course obeys certain rules and is characterized by specific goals. Also, different from the focus group process used methodologies, requirements for the selection of respondents and the researcher and forms of relations between respondents (Zurabishvili, 2006).

The focus group allows us, not just too deeply, to study this or that difficult issue but also to create a clear representation of public opinion on this issue about diversity. Focus group discussions: Respondents' attitudes towards social are better revealed over time. The problem is their psychological attitudes and emotional assessments, which are often not even realized by the respondent (Zurabishvilis, 2006).

The study surveyed 30 students, 30 parents and 20 teachers. For the purpose of data collection, three focus groups were conducted with a total duration of 8 hours. The research questionnaire included 15 open-ended questions.

\section{Research Results}

Respondents share Joshua Stern online education general definition in the study: Introduction of online teaching. And learning (Introduction to Online Teaching and Learning) That is online teaching. Educational which takes place in the internet space. Sometimes it is also called e-learning. Online education can be both e-courses and online universities and colleges, if so. 
How to Enhance the Effectiveness of the Learning Process during Distance Learning. Psychologist Recommendations

Analysis of the collected data revealed that Internet education for learners is mainly associated with the Internet space. With the available resources through which education is possible, based on your own interests. Students, parents and teachers alike point out that online education has many advantages.

Including practicality, affordability, and a wide choice of materials. (Stephen Downes) According to the theory, it is important for people to deepen their knowledge, but for some reason, be it geographical location or lack of time, they do not have the opportunity to master the desired profession or acquire new skills. The disadvantages of online education are the lack of live relationships. Which in turn impairs students' interaction skills with both lecturers and other students.

\section{Conclusions}

In conclusion, we can say that after analyzing the data it turned out that online education for students and their parents, as well as teachers, is a unique opportunity through which it is possible to get an education. Research participants are pretty much actively involved in the online education learning/ teaching process.

Distance learning, as an alternative form of education delivery, is still evolving and improving. The problems that arise in this process are complex and every link school, teacher, parent, and child - contributes to solving them. For the healthy development of students, the focus should be on encouraging communication, reducing feelings of social isolation, and increasing their motivation. Distance learning, as an alternative form of education delivery, is still evolving and improving. The problems that arise in this process are complex and every link - school, teacher, parent, and child - contributes to solving them. For the healthy development of students, the focus should be on encouraging communication, reducing feelings of social isolation, and increasing their motivation.

\section{Acknowledgments}

The author thanks the anonymous reviewers and editor for their valuable contribution.

\section{Funding}

This research received no specific grant from any funding agency in the public, commercial, or not - for - profit sectors.

\section{Author Contributions}

The entire article was written by Tamar Kapanadze. 
Kapanadze, T., (2021)

How to Enhance the Effectiveness of the Learning Process during Distance Learning. Psychologist Recommendations

\section{Disclosure Statement}

The author has not any competing financial, professional, or personal interests from other parties.

\section{References}

1. American Academy of Child and Adolescent Psychiatry. AACAP OFFICIAL ACTION., (2012). Practice Parameter for the Assessment and Treatment of Children and Adolescents with Depressive Disorders, 2007, Review decision date: September 2012.

2. Angold, A. Costello, E.J., (2001) The epidemiology of depression in children and adolescents. In The Depressed Child and Adolescent, 2nd edn. (ed. I. M. Goodyer), pp. 143-178. Cambridge Child and Adolescent Psychiatry series. Cambridge: Cambridge University Press. 40, 443-449.

3. Bonk, C. J., Dennen, V., (2003). Frameworks for research, design, benchmarks, training, and pedagogy in web-based distance education. Handbook of distance education, 331-348.

4. Childers, J. L., Berner, R. T., (2000). General education issues, distance education practices: Building community and classroom interaction through the integration of curriculum, instructional design, and technology. The Journal of General Education, 49(1), 53-65.

5. Europol., (2020). Catching the Virus Cybercrime, Disinformation and the COVID19 Pandemic.

6. Feldman R., (2002). Teaching and Learning Online. A Handbook for UMaas Faculty.

7. Figlio, D., Rush, M., Yin, L., (2013). Is it live or is it Internet? Experimental estimates of the effects of online instruction on student learning. J. Labor Econ. 31, 763-784.

8. Fontaine, R. G., Yang, C., Burks, V. S., Dodge, K. A., Price, J. M., Pettit, G. S., Bates, J. E., (2009). Loneliness as a partial mediator of the relation between low social preference in childhood and anxious/depressed symptoms in adolescence. Development and Psychopathology, 21(2), 479.

9. Garbe, A., Ogurlu, U., Logan, N., Cook, P., (2020). Parents' Experiences with Remote Education during COVID-19 School Closures. American Journal of Qualitative Research, 4(3), 45-65.

10. Garrison, D. R., Kanuka, H., (2004). Blended learning: Uncovering its transformative potential in higher education. The internet and higher education, 7(2), 95-105.

11. Goodenow, C., (1993). Classroom belonging among early adolescent students: Relationships to motivation and achievement. The Journal of early adolescence, 13(1), 21-43.

12. Hall-Lande, J. A., Eisenberg, M. E., Christenson, S. L., Neumark-Sztainer, D., (2007). Social isolation, psychological health, and protective factors in adolescence. Adolescence, 42(166). 
How to Enhance the Effectiveness of the Learning Process during Distance Learning. Psychologist Recommendations

13. Jiao W.Y., Wang L.N., Liu J., Fang S.F., Jiao F.Y., Pettoello-Mantovani M., (2020). Somekh E. Behavioral and emotional disorders in children during the COVID-19 epidemic. J. Pediatr. 2020;221 doi: 10.1016/j.jpeds.2020.03.013. 264-266.e1.

14. Jiao W.Y., Wang L.N., Liu J., Fang S.F., Jiao F.Y., Pettoello-Mantovani M., Somekh E., (2020). Behavioral and emotional disorders in children during the COVID-19 epidemic. J. Pediatr. 2020;221 doi: 10.1016/j.jpeds.2020.03.013. 264266.e1.

15. Kizilcec, R.F., Halawa, S., (2015). Attrition and achievement gaps in online learning, in Proceedings of the Second (2015) ACM Conference on Learning @ Scale (ACM, 2015), pp. 57-66.

16. Lundberg J., (2008). Do Online Students Perform Better than Face-to-face Students?. RUSC Universities and Knowledge Society Journal, 5(1), 35-44.

17. Pfefferbaum B., North C.S., (2020). Mental health and the covid-19 pandemic. N. Engl. J. Med. 2020 doi: 10.1056/NEJMp2008017. NEJMp.2008017.

18. Rios-González C.M., Palacios J.M., (2020). Symptoms of Anxiety and Depression during the Outbreak of COVID-19 in Paraguay.

19. Stern J., (2005). Introduction to Online Teaching and Learning.

20. Qualter, P., Brown, S. L., Munn, P., Rotenberg, K. J., (2010). Childhood loneliness as a predictor of adolescent depressive symptoms: an 8-year longitudinal study. European Child \& Adolescent Psychiatry, 19(6), 493-501.

21. VanLehn, K., (2011). The relative effectiveness of human tutoring, intelligent tutoring systems, and other tutoring systems. Educational Psychologist, 46(4), 197221.

22. Wang G., Zhang Y., Zhao J., Zhang J., Jiang F., (2020). Mitigate the effects of home confinement on children during the COVID-19 outbreak. Lancet. 2020;395:945947. doi: 10.1016/S0140-6736(20)30547-X.

23. Yokoyama, S., (2019). Academic self-efficacy and academic performance in online learning: A mini review. Frontiers in psychology, 9, 2794.

\section{Notes:}

[1] Distance learning - institutional formal education, when a group of students is separated from the teacher and telecommunication systems are used to connect them, provide resources or instructions.

[2] Asynchronous learning - a form of learning when participants in the process do not communicate in one time and space.

[3] Self-efficacy - an individual's selective view of how well he or she can solve a problem and achieve a set goal.

[4] Synchronous learning - a form of learning when participants in a process interact in the same place and space.

[5] The basic premise of a flawless learning technique is to minimize the likelihood of error for the learner. For example, giving a child an assignment that he or she is more likely to complete correctly. 